\title{
Actin Allergen of Common Periwinkle Sea Snail (Littorina littorea)
}

González-Mancebo E ${ }^{1,5}$, Trujillo-Trujillo $\mathrm{MJ}^{1,5}$, GandolfoCano $\mathrm{M}^{1,5}$, Mohedano-Vicente $\mathrm{E}^{1,5}$, Cuesta-Herranz $\mathrm{J}^{2,5}$, Bartolome $\mathrm{B}^{3 *}$, Pastor-Vargas $\mathrm{C}^{4,5 *}$

${ }^{I}$ Allergy Unit, Hospital Universitario de Fuenlabrada, IdiPAZ, Madrid, Spain

${ }^{2}$ Allergy Department, IIS-Fundación Jiménez Díaz, UAM, Madrid, Spain

${ }^{3} R+D$ Department, Roxall, Bilbao, Spain

${ }^{4}$ Department of Immunology, IIS-Fundación Jiménez Díaz, UAM, Madrid, Spain

${ }^{5}$ ARADyAL Network, Instituto de Salud Carlos III, Madrid, Spain

*Both authors should be considered last authors

J Investig Allergol Clin Immunol 2019; Vol. 29(2): 150-152 doi: $10.18176 /$ jiaci.0356

Key words: Shellfish allergy. Mollusk allergy. Periwinkle allergy. Actin. Tropomyosin

Palabras clave: Alergia a marisco. Alergia a moluscos. Alergia a bígaro. Actina. Tropomiosina.

Shellfish are one of the main food allergens in adults and include a diverse group of species with shells or shelllike exo- or endoskeletons. They comprise both crustaceans and mollusks. Mollusks include gastropods (limpets, snails, winkles, and abalone), bivalves (mussels, clams, razor fish, oysters, and scallops), and cephalopods (squid, cuttlefish, and octopus). Shellfish are an important food source and are consumed throughout the world [1]. Japan and other coastal regions of Asia are major mollusk consumers [1]. Countries in southern Europe (Spain, France, Italy, and Portugal) also consume high quantities of mollusks and crustaceans [1]. Mollusk allergies have been documented with gastropods, bivalves, and cephalopods [1]. Although the importance of mollusk allergy is becoming increasingly recognized, its prevalence is unknown. Mollusks were responsible for 5.6\% to $11.7 \%$ of severe allergic reactions in France during 2002 and 2003 and are reported to have caused $36 \%$ of cases of anaphylaxis in Singapore during the same period [1].

The common periwinkle (Littorina littorea) is a marine gastropod mollusk that has gills, an operculum, and a dark and sometimes banded shell. It is a member of the Littorinidae family. Common periwinkles are native to the northeastern coasts of the Atlantic Ocean (northern Spain, France, England, Wales, Scotland, Ireland, Scandinavia, and Russia). They are eaten in coastal areas of Spain, Scotland, England, Wales, and Ireland. Periwinkles are highly valued in African and Asian cuisine. The meat is high in protein and $\omega-3$ fatty acids and low in fat (http: wikipedia.org/wiki/Common_periwinkle).

We report the case of a 49-year-old woman who developed symptoms after consuming periwinkles. Two hours after eating cooked periwinkles (approximately $250 \mathrm{mg}$ ) and 
rice with vegetables at home, she presented with bilateral palpebral angioedema and generalized urticaria, but no other symptoms. She denied having exercised or ingested alcohol or nonsteroidal anti-inflammatory drugs. She was attended in the emergency department, and her symptoms resolved within 3 hours of treatment with intramuscular dexchlorpheniramine and methylprednisolone. Since then, the patient has tolerated all the foods eaten at the time, as well as other shellfish (prawns, razor clams, mussels, and squid), although she has not eaten periwinkle again. She had no previous history of rhinitis or asthma, atopic dermatitis, or food allergy.

Three months later, and after obtaining the patient's informed consent, skin prick tests were performed with commercial extracts from fish (hake, cod, trout, tuna, salmon, sardine, and monkfish), shellfish (prawn, lobster, crab, clam, mussel, snail, and squid), and Anisakis simplex (Roxall Group, Bilbao, Spain). All results were negative. The results of skin prick tests with commercial extracts and prick-by-prick tests with the remaining foods the patient ate were also negative, as were skin prick tests with commercial pollen, mites, dander, and mold extracts. Prick-by-prick tests with raw and cooked periwinkle were both positive (wheal, $5 \mathrm{~mm}$ and $5 \mathrm{~mm}$, respectively). Prick-by-prick tests with raw and cooked mussel, squid, and prawn were negative. Positive and negative results were obtained for controls (histamine and saline respectively). The patient's total serum $\mathrm{IgE}$ was $4 \mathrm{IU} / \mathrm{mL}$, and the results of specific IgE determination with clam, crab, prawn, squid, lobster, and snail were negative $(<0.1 \mathrm{kUA} / \mathrm{L})$ (ImmunoCAP, Thermo Fisher Scientific). The patient refused to undergo oral challenge with periwinkle.

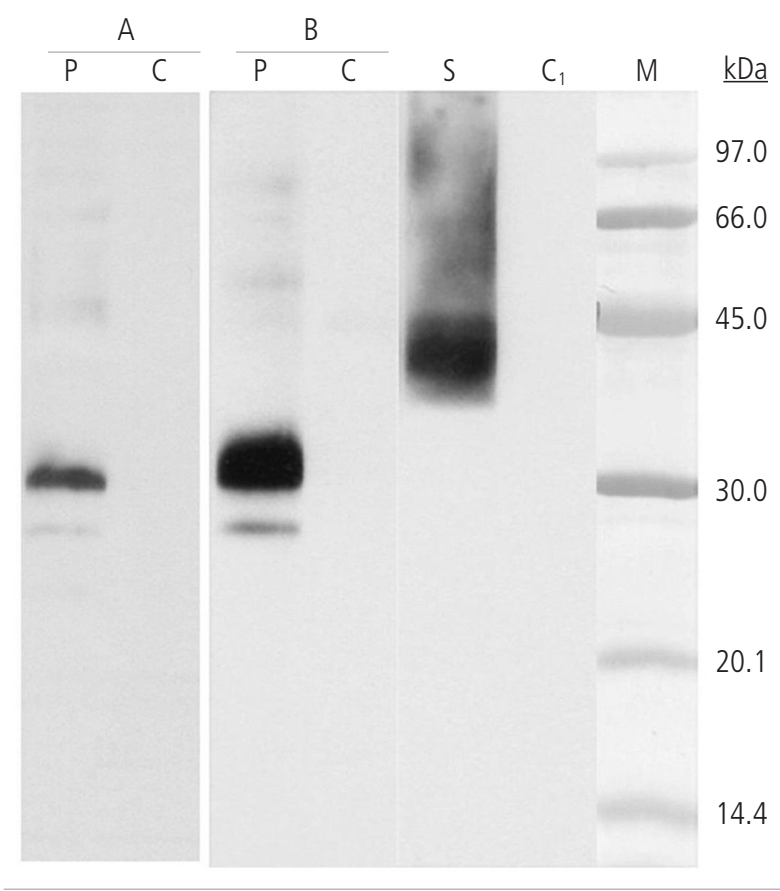

Figure. SDS-PAGE immunoblotting. A, Raw periwinkle extract. B, Cooked periwinkle extract. Lane P, patient's serum; Lane C, control serum (pool of sera from nonatopic individuals); Lane $S$, rabbit serum against Penaeus species tropomyosin; Lane C 1, serum from nonimmunized rabbit; Lane $M$, molecular mass standard.
Raw and cooked protein extracts of L littorea were prepared by homogenization in phosphate-buffered saline (20\% wt/vol), dialyzation, and lyophilization. The extracts were analyzed using SDS-PAGE under reducing conditions (as described by Laemmli), which showed protein bands ranging from $90 \mathrm{kDa}$ to $14 \mathrm{kDa}$ in both extracts (results not shown). SDS-PAGE IgE-immunoblotting assays with both raw and cooked periwinkle extracts revealed an intense IgEreactive band of $31 \mathrm{kDa}$ and a very faint one of $28 \mathrm{kDa}$. An IgG-immunoblotting assay with this extract and rabbit serum against Penaeus species tropomyosin revealed an IgG binding band of $39 \mathrm{kDa}$ (Figure), this result led us to deduce that the 31-kDa IgE-reactive band was not tropomyosin.

The intense $31-\mathrm{kDa}$ IgE-binding protein was manually excised, digested with trypsin, and analyzed by mass spectrometry in tandem, as previously described [2]. Proteins were identified by searching a nonredundant protein sequence database (NCBI). The analysis of the resulting peptides by mass spectrometry revealed the protein to be actin.

Tropomyosin is the allergen most frequently involved in mollusk allergy [3] and is also responsible for most cases of cross-reactivity between mollusks and crustaceans [3]. However, tropomyosin does not appear to be implicated in some patients who are allergic to mollusks but tolerate crustaceans [4]. Cross-reactivity between mollusks is usually found within species of the same class (bivalves, cephalopods, and gastropods) [1]. In addition to tropomyosin, several allergens have been described in mollusks, namely, actin [4], paramyosin [5], myosin heavy chain [6], amylase [7], hemocyanin [8] (amylase and hemocyanin may be involved in cross-reactivity between mollusk and house-dust mite aeroallergens), enolase [4], C1q domain-containing protein [4], arginine kinase [9], and triose phosphate isomerase [10]. At least 3 of these are also allergens in crustaceans, namely, tropomyosin, arginine kinase, and triose phosphate isomerase (www.allergen.org).

We present the case of a patient who was monoallergic to periwinkle and who tolerated all other mollusks and crustaceans tested (negative results in skin prick and specific IgE testing). The heat-stable $31-\mathrm{kD}$ a protein identified as actin was likely responsible for the patient's allergic symptoms. Our review of the literature indicates that this is the first reported case of allergy to common periwinkle sea snail (L littorea).

\section{Funding}

This study was supported by grants from Instituto de Salud Carlos III and the Thematic Network and Cooperative Research Centers ARADyAL RD16/0006/0013 and RD16/0006/0022. The study was cofunded by FEDER grants.

\section{Conflicts of Interest}

The authors declare that they have no conflicts of interest.

\section{References}

1. Khora SS. Seafood-Associated Shellfish Allergy: A Comprehensive Review. Immunol Invest. 2016;4:504-30. 
2. Pastor C, Cuesta-Herranz J, Cases B, Perez-Gordo M, Figueredo $E$, de las Heras $M$, et al. Identification of major allergens in watermelon. Int Arch Allergy Immunol. 2009;149:291-8.

3. Vidal C, Bartolomé B, Rodríguez V, Armisén $M$, Linneberg $A$, González-Quintela A. Sensitization pattern of crustaceanallergic individuals can indicate allergy to molluscs. Allergy. 2015;70:1493-6.

4. Azofra J, Echechipía S, Irazábal B, Muñoz D, Bernedo N, García $B E$, et al. Heterogeneity in allergy to mollusks: a clinicalimmunological study in a population from the North of Spain. J Investig Allergol Clin Immunol. 2017;27:252-60.

5. Suzuki M, Kobayashi Y, Hiraki Y, Nakata H, Shiomi K. Paramyosin of the Disc abalone Haliotis discus discus: identification as a new allergen and cross-reactivity with tropomyosin. Food Chem. 2011;124:921-6.

6. Martins LM, Peltre G, da Costa Faro CJ, Pires EM, da Cruz Inácio FF. The Helix aspersa (brown garden snail) allergen repertoire. Int Arch Allergy Immunol. 2005;136:7-15.

7. Popescu FD. Cross-reactivity between aeroallergens and food allergens. World J Methodol. 2015;5:31-50.

8. Oyelaran $\mathrm{O}$, Gildersleeve JC. Evaluation of human antibody responses to keyhole limpet hemocyanin on a carbohydrate microarray. Proteomics Clin Appl. 2010;4:285-94.

9. Shen HW, Cao MJ, Cai QF, Ruan MM, Mao HY, Su WJ, et al. Purification, cloning, and immunological characterization of arginine kinase, a novel allergen of Octopus fangsiao. J Agric Food Chem. 2012;60:2190-9.

10. Yang Y, Chen ZW, Hurlburt BK, Li GL, Zhang YX, Fei DX, et al. Identification of triosephosphate isomerase as a novel allergen in Octopus fangsiao. Mol Immunol. 2017;85:35-46

Manuscript received July 2, 2018; accepted for publication November 19, 2018.

Eloína González-Mancebo Unidad de Alergia

Hospital Universitario de Fuenlabrada

Fuenlabrada (Madrid), Spain

E-mail: eloina.gonzalez@salud.madrid.org 